\title{
Intraoperative and early postoperative complications in women with stress urinary incontinence treated with suburethral slings: a randomised trial
}

\author{
Jacek K. Szymański, Kornelia Zaręba, Grzegorz Jakiel, Aneta Słabuszewska-Jóźwiak
}

First Department of Obstetrics and Gynaecology, Centre of Postgraduate Medical Education, Warsaw, Poland

Videosurgery Miniinv 2020; 15 (1): 18-29

DOI: https://doi.org/10.5114/wiitm.2019.84702

\begin{abstract}
Introduction: The midurethral sling has become the current standard for the treatment of female stress urinary incontinence.

Aim: To assess intraoperative complications, early post-operative complications as well as the efficacy of tension-free vaginal tape: retropubic and trans-obturator tape procedures.

Material and methods: The analysis involved 91 tension-free vaginal tape (TVT) and 60 transobturator tape (TOT) procedures. Both groups were comparable in terms of patient characteristics, urodynamic results, and preoperative quality of life (QoL) assessment. The complications were registered, and the effectiveness of the procedures was assessed subjectively by the patients at 1-, 3-, 6- and 12-month follow-up.

Results: A significantly lower risk of intraoperative and early post-operative complications was noted in the case of TOT procedures (OR =0.35\%, 95\% Cl: 0.13-0.92). Moreover, regardless of the method used, patients with two or more vaginal deliveries in their history had a reduced risk of complications, as compared to nulliparas and uniparas $(O R=0.38 \%, 95 \% \mathrm{Cl}: 0.16-0.91)$. Previous gynaecological surgery and old age increase the risk of complications with borderline significance ( $O R=2.5,95 \% \mathrm{Cl}: 0.97-6.3 ; O R=2.3,95 \% \mathrm{Cl}: 0.95-5.5$ respectively). The rates of cure, improvement and failure were similar in both groups, as was the significant positive change in post-operative life quality.

Conclusions: TVT and TOT procedures are characterised by a high cure rate and improvement in the post-operative quality of life. However, it seems that the transobturator approach should be the preferred method of treatment of SUI due to the reduced risk of complications, shorter procedure time, and lower intraoperative blood loss.
\end{abstract}

Key words: complications, stress urinary incontinence, transobturator tape, surgical outcomes, tension-free vaginal tape.

\section{Introduction}

Stress urinary incontinence (SUI) affects approximately $50 \%$ of women who suffer from urinary incontinence (UI) [1]. Stress urinary incontinence significantly decreases a woman's quality of life and sexual functioning. Mid-urethral sling (MUS) surgery has become the current standard for treatment of female stress urinary incontinence. In 1995, Ulmsten and Petros [2], based on their own Integral Theory, introduced the retropubic tension-free vaginal tape (TVT). In 2001, Delorme [3] defined the transobturator tape procedure (TOT) and in 2003, De Leval [4] modified this method, introducing the inside-out transobturator tape placement technique. 
The effectiveness of MUS was compared to Burch colposuspension, which previously constituted the gold standard in SUI treatment. Ustun et al. [5] reported $83 \%$ efficacy of both these procedures at 3-month follow-up. The long-term (8-year) observation of Jelovsek et al. confirmed a similar efficacy of TVT and laparoscopic Burch for the treatment of SUI. However, considering the shorter surgery duration, shorter hospital stay for the TVT procedure, and longer learning curve for Burch colposuspension, MUS should be favoured in stress urinary incontinence therapy [6]. Laparoscopic Burch should be preferred in the case of other concurrent pelvic surgery, in the suspicion of bowel adhesions close to the retropubic space, in women considering pregnancy, and in the case of an allergic reaction to polypropylene.

Usually complications are categorised as intraoperative (bladder, urethral, vessel, and bowel injury), immediate postoperative (voiding dysfunction, groin pain, infection, and necrotizing fasciitis), and chronic problems (de novo urgency, sling erosion) [7]. The use of the obturator foramen entails very limited intraoperative damage to the urinary bladder but this still has not eliminated other intraoperative complications. A meta-analysis of TVT complications versus other treatments performed by Novara et al. [8] showed that bladder perforations, pelvic haematomas, and storage problems were less common after TOT. Similar data was presented in a recent Cochrane review; however, data concerning the need for repeat incontinence surgery in the long term, which was more likely in the case of the TOT than the TVT procedure, were equally limited [9].

\section{Aim}

The purpose of this study was to analyse intraoperative and early post-operative complications associated with SUI surgery, and to identify risk factors for complications. The early post-operative period was defined as 7 days after surgery. Evaluation of the short-term efficacy of retropubic and transobturator midurethral slings was also performed.

\section{Material and methods}

In our study, 151 women who had undergone an MUS procedure over the period of 2015-2017 were subject to post-operative evaluation. Two groups of patients were identified: group 1 - treated using a TVT technique (91 patients), and group 2 - treated using a TOT technique (60 patients). The procedures were performed in St. Sophia Hospital in Warsaw by two gynaecological surgeons with 15 years of experience in urogynaecological surgery, using the same surgical technique. The surgeons and the patients were randomly assigned to the procedure.

The TVT procedure was performed as described by Ulmsten and Petros, including a cystoscopy, and TVT-O was carried out according to de Leval. In both groups, more than $80 \%$ of the procedures were performed under spinal anaesthesia.

The following pre-surgical data were included: age, body mass index (BMI), parity, symptom duration, cigarette smoking, menopausal status, hormonal replacement therapy, oral contraception, previous gynaecological surgery, and relevant comorbidities. The preoperative assessment also included: Pelvic Organ Prolapse Quantification (POPQ), 1-hour pad test, urodynamic testing: cystometry, uroflowmetry, profilometry, and pelvic floor ultrasound. Patients with urodynamically confirmed urinary stress incontinence (a stable detrusor, maximum urethral closure pressure (MUCP) $<30 \mathrm{~cm} \mathrm{H}_{2} \mathrm{O}$, Valsalva leak point pressure (VLPP) $<90 \mathrm{~cm} \mathrm{H}_{2} \mathrm{O}$, maximum flow rate $\left(\mathrm{Q}_{\max }\right)>17 \mathrm{ml} / \mathrm{s}, 1$-hour pad test $>2 \mathrm{~g}$ ) and a hypermobile urethra were enrolled in the study. The exclusion criteria were as follows: detrusor overactivity, a post-void residual volume (PVR) $>100 \mathrm{ml}$, bladder outlet obstruction (BOO), hypomobility of the urethra, and a negative pad test. The quality of life evaluation was performed with the help of the Incontinence Impact Questionnaire, Short Form (IIQ-7) and the Visual Analogue Scale (VAS) before surgery and 12 months after surgery. The subjective outcomes were evaluated 1, 3, 6, and 12 months after treatment. Other aspects were also assessed: the time of the surgery, blood loss, hospital stay duration, and the type of perioperative complications. The intraoperative blood loss was evaluated using a calibrated plastic bag attached to the patient's buttocks. Additionally, the number of gauze pads was strictly calculated considering that $10 \times 10 \mathrm{~cm}$ contains $60 \mathrm{ml}$ of blood. Subjective outcomes were self-evaluated by the patients within $1,3,6$, and 12 months after surgery according to the schedule proposed by the authors (Table I).

The quality of life was evaluated using the Short Form IIQ-7 and the VAS scale before and 6 months after surgery. The VAS interview question was: "How would you feel if your urinary system remained as 
Table I. Self-assessment scale

\begin{tabular}{|lc|}
\hline Points & SUI/UUI \\
\hline 0 & Cure \\
\hline 1 & Improvement \\
\hline 2 & Failure \\
\hline 3 & Worsening \\
\hline
\end{tabular}

SUI - stress urinary incontinence, $\mathrm{UUI}$ - urgency urinary incontinence.

Table II. Characteristics of TVT and TOT groups

\begin{tabular}{|c|c|c|}
\hline Parameter & $\begin{array}{c}\text { TVT } \\
(n=91)\end{array}$ & $\begin{array}{c}\text { TOT } \\
(n=60)\end{array}$ \\
\hline \multicolumn{3}{|l|}{ Age: } \\
\hline Min.-max. & $35-83$ & $33-84$ \\
\hline Average \pm SD & $59 \pm 10.9$ & $60.6 \pm 11.5$ \\
\hline \multicolumn{3}{|l|}{ BMI: } \\
\hline Min.-max. & $21.2-43.0$ & $19.7-40.8$ \\
\hline Average \pm SD & $28.1 \pm 4.6$ & $27.2 \pm 3.6$ \\
\hline \multicolumn{3}{|l|}{ Symptom duration: } \\
\hline Min.-max. & $0.5-30$ & $0.5-20$ \\
\hline Median $(25 \%, 75 \%)$ & $4(2,7)$ & $4(2,7)$ \\
\hline Cigarette smoking & 15 (16.0\%) & 9 (15.0\%) \\
\hline \multicolumn{3}{|l|}{ Menopausal status: } \\
\hline Min.-max. & $0-34$ & $0-37$ \\
\hline Median $(25 \%, 75 \%)$ & $7(0,16)$ & $7(1.5,19)$ \\
\hline Internal diseases & $67(74.0 \%)$ & $47(78.0 \%)$ \\
\hline HRT & $9(10.0 \%)$ & $13(22.0 \%)$ \\
\hline $\mathrm{OC}$ & $1(1.0 \%)$ & 0 \\
\hline \multicolumn{3}{|l|}{ Deliveries: } \\
\hline Min.-max. & $0-4$ & $0-5$ \\
\hline Median (25\%, 75\%) & $2(1,2)$ & $2(1,3)$ \\
\hline Pelvic organ prolapse & $36(39.0 \%)$ & $29(48.0 \%)$ \\
\hline \multicolumn{3}{|l|}{ Previous: } \\
\hline Abdominal hysterectomy & $6(7.0 \%)$ & $2(3.0 \%)$ \\
\hline Vaginal hysterectomy & $1(1.0 \%)$ & $1(2.0 \%)$ \\
\hline Surgery for prolapse & $5(5.0 \%)$ & $2(3.0 \%)$ \\
\hline \multicolumn{3}{|l|}{ Coexistent surgery: } \\
\hline Anterior colporraphy & $36(40.0 \%)$ & $27(45.0 \%)$ \\
\hline Vaginal hysterectomy & $5(5.0 \%)$ & $6(10.0 \%)$ \\
\hline Supraspinal vaginopexy & $3(3.0 \%)$ & $4(7.0 \%)$ \\
\hline LAVH & $2(2.0 \%)$ & $1(2.0 \%)$ \\
\hline
\end{tabular}

HRT - hormonal replacement therapy, OC - oral contraceptives. it is today for the rest of your life?" The answers ranged from 0 - very good, to 10 - terrible.

The study had the approval of the Hospital Ethics Committee and the informed consent of individual patients was duly obtained. The study was not registered as a clinical trial because it was based on current clinical practice and all the procedures used to treat the patients in the study were consistent with current clinical standards.

\section{Statistical analysis}

The tested parameters were described with the mean and standard deviation (SD) or the median and interquartile range in the case of data of continuous nature, as well as scales of frequency in the case of categorical data.

In order to compare the specified parameters, the following statistical tests were used: Wilcoxon signed rank sum test, the Mann-Whitney $U$ test, Pearson's $\chi^{2}$ test, or Fisher's exact test, the test of marginal factorisation, Spearman's correlation coefficient, and the logistic regression model. For the gradual elimination method at a level of 0.1 in order to stay within the scale, statistical factors at a level of 0.05 were used. All tests were bilateral, a $5.0 \%$ level of significance was decided. The power analysis was calculated assuming a standard change of 6 points on the Visual Analogue Scale (VAS). A change of 2 points was considered as being clinically significant. An analysis of the two groups containing 91 and 60 subjects, respectively, was sufficient to obtain a power of $80 \%$ to detect the difference between -6.0 and $-7.4(S D=3)$. It means that the study has adequate power to detect a statistically significant difference.

\section{Results}

\section{Characteristics of patients}

Most patients undergoing SUI surgery were aged between 33 and 84 years (mean age: 59.6) in both groups. The body mass index was $28.1 \pm 4.6$ in group 1 , and $27.2 \pm 3.6$ in group 2. The duration of the median signs and symptoms was $4 \pm 2.7$ years and it was similar in both groups. The menopausal status (median 7 years) as well as the smoking history were also comparable for both groups. The BMI results in the TVT and the TOT groups were similar: $28.1 \pm 4.6 \mathrm{~kg} / \mathrm{m}^{2}$, and $27.7 \pm 3.6 \mathrm{~kg} / \mathrm{m}^{2}$, respectively. No differences 
Table III. Surgery duration, intraoperative blood loss, and hospital stay duration in TVT and TOT groups

\begin{tabular}{|lccc|}
\hline Parameter & TVT $(n=91)$ & TOT $(n=60)$ & $P$-value* \\
\hline Surgery duration [min]: & $20-90$ & 0.0001 \\
\hline Min.-max. & $35(30,45)$ & $20(20,25)$ & 0.006 \\
\hline Median (25\%, 75\%) & & & \\
\hline Blood loss [ml]: & $22(44.0 \%)$ & $22(79.0 \%)$ & 0.08 \\
\hline 50 & $23(46.0 \%)$ & $4(14.0 \%)$ & $2(7.0 \%)$ \\
\hline 100 & $5(10.0 \%)$ & & $1-7$ \\
\hline 150 and more & $1-11$ & $2(1,3)$ \\
\hline Hospital stay duration [days]: & $2(1,4)$ & \\
\hline Median.-max. $25 \%, 75 \%)$ & & & \\
\hline
\end{tabular}

${ }^{\star} P<0.05$ was considered statistically significant

were observed between the tested groups in the aspect of parity (median 2), previous gynaecological surgery or pelvic organ prolapse (Table II).

The result of the 1-hour pad test ranged from $2 \mathrm{~g}$ to $617 \mathrm{~g}$. The medians in group 1 and 2 were $36.7 \mathrm{~g}$ and $13.3 \mathrm{~g}$, respectively, with no statistical significance. Almost $70 \%$ of the tested patients in both groups had pad test results higher than $10.0 \mathrm{~g}$.

Urodynamics confirmed SUI in all the women included in the study. A stable detrusor as well as a negative urethral closure pressure were revealed in all cases. Normal emptying of the bladder was recognised among all patients with a measured PVR volume of $<50 \mathrm{ml}$.

The time of the TVT procedure was significantly longer than the TOT procedure, the medians were $35 \mathrm{~min}$ and 20 min $(p=0.0001)$, respectively. Intraoperative blood loss in the group of patients who underwent TOT was lower compared to the TVT group $(p=0.006)$. The hospital stay was similar in both groups with the median of 2 days $(p=0.08)$ (Table III).

\section{Intraoperative and early post-operative complications}

Intraoperative and early post-operative complications occurred in the TVT and TOT groups in 25.0\% and in $12.0 \%$ of patients.

Urinary bladder perforation occurred in 5 patients but only in the TVT group. A haemorrhage from the obturator foramina was observed (Table IV) in one case in the TOT group. During the first day after the surgery, 3 (3.0\%) TVT patients were unable to urinate spontaneously, while voiding difficulties occurred in about $10.0 \%$ of TVT patients and in $5.0 \%$ of the group of TOT patients.

The most common procedure performed in the complications described above was catheterisation of the urinal bladder. Among the TVT group, the majority of patients (5.0\%) had to be catheterised for 3 days, while prolonged catheterisation was neces-

Table IV. Intraoperative and early post-operative complications

\begin{tabular}{|c|c|c|}
\hline $\begin{array}{l}\text { Intraoperative and early } \\
\text { post-operative complications }\end{array}$ & $\begin{array}{c}\text { TVT } \\
(n=91)\end{array}$ & $\begin{array}{c}\text { TOT } \\
(n=60)\end{array}$ \\
\hline Total & $23(25.0 \%)$ & $7(12.0 \%)$ \\
\hline \multicolumn{3}{|l|}{ Intraoperative complications: } \\
\hline Single urinal bladder perforation & $4(4.0 \%)$ & 0 \\
\hline Double urinal bladder perforation & $1(1.0 \%)$ & 0 \\
\hline Intraoperative haemorrhage & 0 & $1(2.0 \%)$ \\
\hline \multicolumn{3}{|l|}{ Early post-operative complications: } \\
\hline Urinal retention & $3(3.0 \%)$ & 0 \\
\hline Voiding difficulties & $9(10.0 \%)$ & $3(5.0 \%)$ \\
\hline Urgency, frequency & $1(1.0 \%)$ & $1(2.0 \%)$ \\
\hline Stress urinary incontinence & $1(1.0 \%)$ & $2(3.0 \%)$ \\
\hline PVR > $1000 \mathrm{ml}$ & $2(2.0 \%)$ & 0 \\
\hline Subcutaneous haematoma & $1(1.0 \%)$ & 0 \\
\hline Retzius space haematoma & $1(1.0 \%)$ & 0 \\
\hline Urinary tract infection & $1(1.0 \%)$ & 0 \\
\hline
\end{tabular}


Table V. Subjective outcomes in TVT and TOT groups

\begin{tabular}{|c|c|c|}
\hline Parameter & $\begin{array}{c}\text { TVT } \\
(n=91)\end{array}$ & $\begin{array}{c}\text { TOT } \\
(n=60)\end{array}$ \\
\hline SUI after 1 month: & $n=90$ & $n=60$ \\
\hline 0 & 79 (88.0\%) & $53(88.0 \%)$ \\
\hline 1 & $3(3.0 \%)$ & $6(10.0 \%)$ \\
\hline 2 & $8(9.0 \%)$ & $1(2.0 \%)$ \\
\hline UUI after 1 month: & $n=90$ & $n=60$ \\
\hline 0 & $72(80.0 \%)$ & $43(78.0 \%)$ \\
\hline 1 & 7 (8.0\%) & $4(7.0 \%)$ \\
\hline 2 & $11(12.0 \%)$ & $9(15.0 \%)$ \\
\hline SUI after 3 months: & $n=90$ & $n=60$ \\
\hline 0 & 77 (86.0\%) & 57 (95.0\%) \\
\hline 1 & $6(7.0 \%)$ & $1(2.0 \%)$ \\
\hline 2 & $6(7.0 \%)$ & $2(3.0 \%)$ \\
\hline 3 & $1(1.0 \%)$ & 0 \\
\hline UUI after 3 months: & $n=90$ & $n=60$ \\
\hline 0 & $75(83.0 \%)$ & $49(82.0 \%)$ \\
\hline 1 & $4(4.0 \%)$ & $2(3.0 \%)$ \\
\hline 2 & $11(12.0 \%)$ & $9(15.0 \%)$ \\
\hline SUI after 6 months: & $n=89$ & $n=60$ \\
\hline 0 & $78(88.0 \%)$ & $57(95.0 \%)$ \\
\hline 1 & $2(2.0 \%)$ & $1(2.0 \%)$ \\
\hline 2 & $9(10.0 \%)$ & $2(3.0 \%)$ \\
\hline UUI after 6 months: & $n=89$ & $n=60$ \\
\hline 0 & 77 (87.0\%) & $53(88.0 \%)$ \\
\hline 1 & $3(3.0 \%)$ & $1(2.0 \%)$ \\
\hline 2 & $9(10.0 \%)$ & $6(10.0 \%)$ \\
\hline SUI after 12 months: & $n=79$ & $n=42$ \\
\hline 0 & $73(92.0 \%)$ & $41(98.0 \%)$ \\
\hline 1 & $5(6.0 \%)$ & $1(2.0 \%)$ \\
\hline 2 & $1(1.0 \%)$ & 0 \\
\hline UUI after 12 months: & $n=79$ & $n=42$ \\
\hline 0 & $68(86.0 \%)$ & $40(95.0 \%)$ \\
\hline 1 & $3(4.0 \%)$ & 0 \\
\hline 2 & 7 (9.0\%) & $2(5.0 \%)$ \\
\hline 3 & $1(1.0 \%)$ & 0 \\
\hline
\end{tabular}

sary in $4.0 \%$ for a period up to 14 days. In 2 (2\%) cases dilatation of the urethra had to be performed. One of the patients after 14 days of catheterisation (under suspicion of erosion of the urethra - which was not confirmed later) had to be catheterised due to urinal retention until the urethrolysis, which took place 3 months after surgery. A PVR of $1000 \mathrm{ml}$ was observed in 2 of the patients from the TVT group who had been catheterised. In the post-TOT procedure group, $3(5.0 \%)$ patients had to be catheterised once. Altogether, extra catheterisation was performed in groups 1 and 2, in 18\% and in 5.0\% of the women, respectively. In the early postoperative period, urgency de novo was observed in $1.0 \%$ and in $2.0 \%$ of patients who underwent TVT and TOT procedures, respectively. In several cases, the following complications occurred after the TVT procedure: subcutaneous hematoma with abscesses, and Retzius' space haematoma. Such complications were not observed in patients who had the TOT procedure (Table IV).

The subjective cure and failure rates were similar in both groups ( $p=0.065-0.92)$. After the first month, $88.0 \%$ of women in both groups were subjectively cured, $3.0 \%$ in group 1 , and $10.0 \%$ in group 2 showed an improvement, while $9.0 \%$ who underwent TVT, and $2.0 \%$ who had TOT procedures did not show any change. Persistent urgency was reported in a similar percentage of patients in both groups: $20.0 \%$ and $22.0 \%$ who had TVT and TOT procedures, respectively. Voiding difficulties were observed in $1(1.1 \%)$ patient who underwent a TVT procedure, and one patient from the same group was also unable to urinate. This patient was later qualified for urethrolysis. The 6- and 12-month follow-ups revealed that more than $80.0 \%$ of the patients were completely dry with no symptoms of urgency; however, after 12 months, $20.0 \%$ of the patients were lost from follow-up (Table V).

\section{Quality of life assessment}

Before the surgery, the median of the answers on the VAS was 9, close to "terrible", and was similar in both groups. A 6-month follow-up revealed a significant improvement in life quality (median 1 in both groups, $p<0.0001)$. The change in both groups was comparable $(p=0.97)$ (Table VI).

The impact of UI on everyday activities was assessed using the short form IIQ-7. Results equal to and below 14 were classified as satisfactory. Before the surgery, the median in groups 1 and 2 was 16 
and 13 , respectively. After the surgery, the quality of life significantly increased (the median after the procedure in both groups (VAS) was $2 ; p<0.0001$ ) and no significant difference between the groups was noted $(p=0.97)$. Moreover, a very strong linear relationship was revealed in both groups between the level of changes in the SF IIQ-7 and the QoL (Spearman's rho $=-0.68$ and $-0.96, p<0.0001$, for patients who had undergone both the TVT and the TOT procedures). The worse the QoL was before the procedure, the bigger the improvement that was achieved (Figures 1, 2).

Table VI. QoL before and after surgery in TVT and TOT groups: VAS, SF IIQ-7

\begin{tabular}{|c|c|c|}
\hline Parameter & $\begin{array}{c}\text { TVT } \\
(n=91)\end{array}$ & $\begin{array}{c}\text { TOT } \\
(n=60)\end{array}$ \\
\hline \multicolumn{3}{|l|}{ Evaluation before surgery (VAS): } \\
\hline Min.-max. & $4-10$ & $1-10$ \\
\hline Median $(25 \%, 75 \%)$ & $9(8,10)$ & $9(8,10)$ \\
\hline \multicolumn{3}{|l|}{ Evaluation after surgery (VAS): } \\
\hline Min.-max. & $0-10$ & $0-10$ \\
\hline Median $(25 \%, 75 \%)$ & $1(1,3)$ & $1(1,2.5)$ \\
\hline Difference: before vs. after surgery & $p<0.0001$ & $p<0.0001$ \\
\hline \multicolumn{3}{|l|}{ Change: } \\
\hline Min.-max. & $-10--2$ & $-10-0$ \\
\hline Median (25\%, 75\%) & $-7(-8,-5)$ & $-7(-9,-5)$ \\
\hline TVT vs. TOT & $p=0.97$ & \\
\hline \multicolumn{3}{|l|}{ QoL before surgery (IIQ-7): } \\
\hline Min.-max. & $0-28$ & $0-28$ \\
\hline Median (25\%, 75\%) & $16(10,20)$ & $13(5.5,21.5)$ \\
\hline \multicolumn{3}{|l|}{ QoL after surgery (IIQ-7): } \\
\hline Min.-max. & $0-28$ & $0-12$ \\
\hline Median (25\%, 75\%) & $2(1,4)$ & $2(1,3)$ \\
\hline \multicolumn{3}{|l|}{ Level of changes: } \\
\hline Min.-max. & $-26-9$ & $-24-2$ \\
\hline Median (25\%, 75\%) & $-11(-17,-4)$ & $-12(-19,-4)$ \\
\hline TVT vs. TOT & $p=0.95$ & \\
\hline Spearman's rank correlation & Rho $=-0.68$ & $8 \mathrm{Rho}=-0.96$ \\
\hline Change: before vs. after surgery & $p<0.0001$ & $p<0.0001$ \\
\hline
\end{tabular}

An analysis was performed of the correlations between the occurrence of intraoperative and/or early post-operative complications and chosen clinical subjects (such as: type of surgery, age, duration of SUI symptoms, deliveries, amount of previous gynaecological procedures, cigarette smoking, BMI, 1 -hour pad test). The reference group comprised patients who underwent a TVT procedure, were aged $\leq 58$ (the median was used as the cutting point), with a duration of signs and symptoms of $\leq 4$ years, who had never given birth, had no comorbidities, with a pad test result of $\leq 27 \mathrm{~g}$ (median), non-smokers, with no previous gynaecological surgery, and a BMI of $<25$ (Table VII).The adjustment of the model was checked by the Hosmer-Lemeshow test $(p=0.94)$, showing good fit, whereby its prediction value, measured by the area under the ROC curve, came to 0.73 .

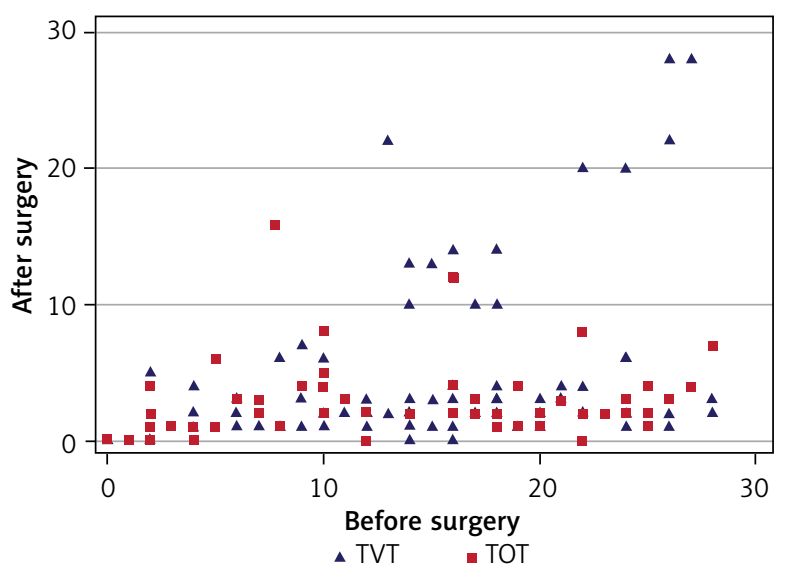

Figure 1. Life quality evaluation before and after the surgery in both groups

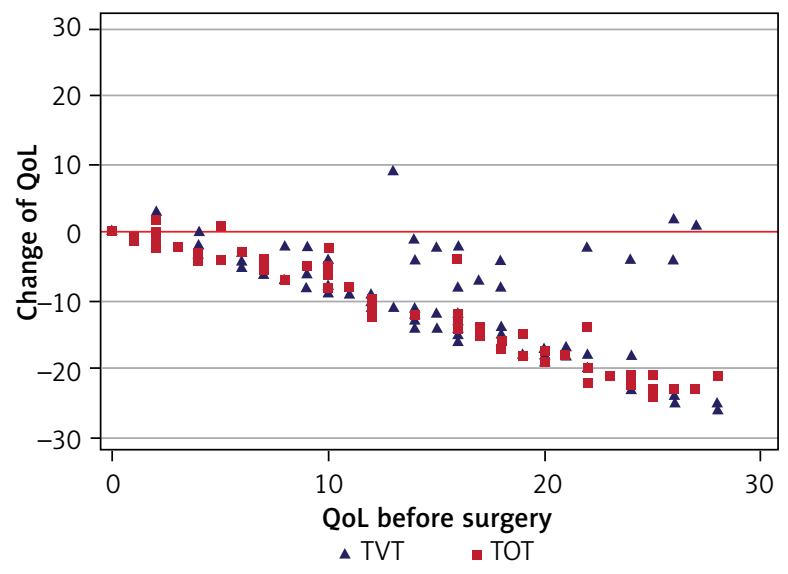

Figure 2. Changes of the evaluation of life quality after surgery in both groups 
Table VII. Analysis of the logistic model to predict complications ( $n=151,30$ complications)

\begin{tabular}{|c|c|c|}
\hline Parameter & OR $(95 \% \mathrm{Cl})$ & $P$-value \\
\hline Type of surgery TOT vs. TVT & $\begin{array}{c}0.35 \\
(0.13-0.92)\end{array}$ & 0.033 \\
\hline Age $>58$ vs. $\leq 58$ & $\begin{array}{c}2.3 \\
(0.95-5.5)\end{array}$ & 0.066 \\
\hline Duration of illness > 4 vs. $\leq 4$ & & $>0.1$ \\
\hline \multicolumn{3}{|l|}{ Births given: } \\
\hline 2 or more vs. $0-1$ & $\begin{array}{c}0.38 \\
(0.16-0.91)\end{array}$ & 0.031 \\
\hline Pad test $>27$ vs. $\leq 27$ & & $>0.1$ \\
\hline Cigarette smoking & & $>0.1$ \\
\hline $\begin{array}{l}\text { No. of gynaecologic surgical } \\
\text { procedures }\end{array}$ & $\begin{array}{c}2.47 \\
(0.97-6.33)\end{array}$ & 0.06 \\
\hline \multicolumn{3}{|l|}{$\mathrm{BMI}[\mathrm{kg}]:$} \\
\hline $25-29.9$ vs. under 25 & & $>0.1$ \\
\hline 30 and more vs. under 25 & & $>0.1$ \\
\hline
\end{tabular}

Adjustment of model H-L: $p=0.94$. Field under ROC $=0.73$.

Patients who underwent the TOT procedure are significantly less likely to develop intraoperative and early post-operative complications than patients who have had a TVT procedure $(\mathrm{OR}=0.35,95 \% \mathrm{Cl}$ : 0.13-0.92). Additionally, regardless of the method of surgery, patients who have given birth to two or more children have a statistically significantly lower chances of developing complications than patients who have either never given birth or have given birth to one child only $(\mathrm{OR}=0.38,95 \% \mathrm{Cl}: 0.16-0.91)$. Patients with gynaecological surgery in their medical history as well as older patients are at greater risk of complications $(\mathrm{OR}=2.5,95 \% \mathrm{Cl}$ : 0.97-6.3, $\mathrm{OR}=2.3$, 95\% Cl: 0.95-5.5, accordingly). Other factors had no impact on intraoperative and post-operative complications.

\section{Discussion}

Optimally, surgery should be effective, easy to perform, with a short period of convalescence, and without complications. Since the publication of the Integral Theory, tension-free suburethral tape has become the gold standard in the treatment of SUI. In the analysis performed by de Tayrac and Madelenat [10], suburethral tapes were used in $83.9 \%$ of women with stress urinary incontinence. In this report, based on the evaluations of 1,224 procedures, it was found that $59.7 \%$ of patients were treated with TVT, and $21.1 \%$ with TOT. The previous published literature shows that both procedures are equally therapeutically effective [11-13]. It appears from clinical and theoretical data that the horizontal placement of the tape in the TOT procedure should eliminate the risk of intraoperative damage to the urinal bladder and reduce post-operative voiding difficulties [14]. Previous studies suggest that TOT is less effective in women with a hypomobile urethra [15]. Thus, to obtain two comparable groups, patients with decreased mobility of the urethra (assessed using ultrasound imaging of the pelvic floor) were excluded from the study.

In the current study, both the TVT and TOT techniques were analysed to assess intraoperative and post-operative complications and to identify possible risk factors for complications. The impact on the quality of life of both procedures was also evaluated.

Intraoperative and post-operative complications were observed in $25 \%$ of the patients who had undergone the TVT procedure and in $12 \%$ who were operated on according to the TOT method. Other authors $[13,16-18]$ report a high percentage of all complications associated with the TVT procedure: between $5.0 \%$ and $43.1 \%$. Intraoperative complications were noted in 2.9-12.9\% [9, 13, 19, 20]. In our study, intraoperative complications were observed in $5.0 \%$ of patients who underwent TVT surgery, significantly more often than in those who had a TOT procedure $(p=0.033)$. All of them concerned the perforation of the urinal bladder, and 1 patient even had two perforations of the bladder. Urinal bladder perforation is one of the most common intraoperative complications. Studies have demonstrated this in $0.7-24 \%$ of TVT procedures [17, 21-23]. Our result is consistent with the one reported by Ford et al. [9] (4.5\%), who analysed 8,652 TVT procedures. Bladder perforation was detected by cystoscopy and the application needle was reinserted properly. The indwelling Foley catheter was left in situ for one to several days. In the study of McLennan et al. [24], the pivotal risk factor for bladder injury was surgeon inexperience. It is imperative that residents are given appropriate training in suburethral tape procedures and cystoscopy. The age and weight of the patients were also significantly associated with perforation, where the group of women with a bladder injury was 
4.5 years younger and $7.86 \mathrm{~kg}$ lighter. Some authors suggest various modifications of the TVT procedure to reduce the risk of cystotomy. Ras et al. [25] reported a beneficial effect of a large $(2 \times 180 \mathrm{ml}$ of saline with bupivacaine and adrenaline) bilateral space of Retzius infiltration. McLennan et al. [26] proposed an abdominal needle placement (top- down) instead of the vaginal (bottom-up) approach.

Urinal bladder perforation is very rare in TOT procedure cases. Luo et al. [22] and Aigmüller et al. [20], who analysed cumulatively 512 TOT procedures, reported perforation of the urinal bladder in $0-1.1 \%$. In the TOT group within our study, this complication was not noted at all. The only observed intraoperative complication was a haemorrhage from the obturator foramina, which occurred in 1 case only (2.0\%) and required compression from the vaginal approach. Gomes et al. [17] observed this complication in $0-2.0 \%$ of cases, which confirms our own observations. The retropubic approach increases the risk of vessel injury that in the case of hemodynamic significant haemorrhage requires aggressive treatment involving a laparotomy and a blood transfusion. Most cases of mild and moderate bleeding can be successfully treated with vaginal packing although they could result in haematomas of different sizes. Only large, symptomatic haematomas require surgical drainage, while most that are smaller than $100 \mathrm{ml}$ in volume could be effectively treated conservatively [17]. Different studies report similar incidence of haematomas ranging from $0.9 \%$ to $1.7 \%$ of patients [27, 28]. Giri et al. [29] observed haematomas in the retropubic space using MRI in $16.6 \%$ of post-TVT patients without clinical symptoms. It seems that this complication occurs more often than it is assumed. It can also result in voiding difficulties experienced after surgery.

In our study, early post-operative complications occurred in $20 \%$ of the patients in the TVT group but only in $8.0 \%$ of the patients in the TOT group. Other studies have revealed early post-operative complications after a TVT procedure in 2.9 to $19.5 \%$ [11, 17, 21, 27, 30]. Bianchi-Ferraro et al. [31] noted early post-operative urinal retention, urinary tract infections, groin pain, and urgency de novo in 3.5\%, $7.1 \%, 26.7 \%$, and $3.5 \%$ of patients, respectively. In our study, urinal retention was not observed in the TOT group. Complications with micturition were noted in $5.0 \%$ of the women, urgency de novo in $2.0 \%$, and persistence of SUI in $3.0 \%$ of the patients. In the TVT group, post-operative problems with micturition were observed in $14.0 \%: 3.0 \%$ of the patients suffered from dysuria, $10.0 \%$ reported voiding difficulties, and urgency de novo was noted in $1.0 \%$. The range in which urinary retention is reported is wide, from $2.2 \%$ to $4.4 \%[11,21,27]$, as is that for post-operative problems with micturition, from $1.0 \%$ to $28.0 \%$ [32, 33]. In transobturator tape placement, the risk of urinary retention is lower than in the case of the TVT procedure, and varies from $1.0 \%$ to $11.0 \%$ $[17,34,35]$. In our study, $5.0 \%$ of the patients in the TOT group reported problems with micturition. Other authors have reported micturition problems in 1.1\% to $24.0 \%$ of patients $[9,27,33,36,37]$. Surprisingly, Laurikainien et al. [38] observed a statistically longer convalescence to normal micturition in the TOT group compared to the TVT group. Tape mobilization to decrease the suburethral tension appears to be an effective treatment for urinary retention and voiding difficulties if clean intermittent catheterization is insufficient. Price et al. suggest pulling down the tape within 14 days of surgery [39]. In our practice, similarly to Barisiene et al. [18], we mobilised the sling within 1 week postoperatively. Ripperda et al. [40] tried to identify the predictive factors of early postoperative voiding dysfunction. It seems that current medical comorbidities and an increasing postvoid residual volume during pressure-flow studies at the preoperative urodynamic assessment increase the risk of initial voiding trial failure, leading to postoperative urinary tract infections and the development of acute urinary retention.

Urgency de novo has an enormous impact on quality of life. In our study, this complication was observed in $1.0 \%$ of the women in the TVT group and in $2.0 \%$ of the patients in the TOT group. Similar observations were reported by Khan et al. [41], Cavkaytar et al. [11], and Canete et al. [42]. The percentage of urgency de novo varied from $1.6 \%$ to $3.3 \%$ after a TVT procedure and 2.0 to 7.7 after a TOT procedure. The differences between the analysed groups were not statistically significant. The pathophysiology of overactive bladder (OAB) de novo is not completely clear. Some authors suggest that $O A B$ symptoms could be overlooked during initial clinical assessment. Tape incision seems to be less effective when compared with the same procedure for urinary retention and voiding difficulties. Some patients with urgency de novo benefit from anticholinergics or $\beta_{3}$-receptor agonists [43]. 
Urinary tract infections (UTIs) are observed in $0.4-21.4 \%$ of patients in the post-operative period $[13,22,31,44,45]$. In our study, UTI was noted in $1(1.0 \%)$ patient in the TVT group. It seems that urine tests (and a urine culture, if needed) should be performed along with antibiotic prophylaxis before surgery. Cases of recurrent UTIs caused by bladder outlet obstruction or erosion require removal of the tape.

Our study revealed that patients who underwent the TOT procedure have significantly lower chances of intraoperative and early post-operative complications. This can be explained by the lower percentage of urinal bladder perforations and fewer voiding difficulties after surgery in this group of patients. In the studies of Ben Zav et al. [21] and Luo et al. [22], damage to the urinal bladder was only observed during the TVT procedure. In our material, post-operative urine retention occurred twice as many times as among patients who underwent TVT, whereas Ben Zvi et al. [21] and Cavkaytar et al. [11] observed this kind of complication in an equal percentage among patients operated on using the TOT and TVT procedure. This problem remains unsolved and requires further well-designed studies.

Older patients and women with a history of gynaecological surgery have a higher risk of complications irrespective of the procedure performed. It is possible that changes of anatomical conditions in the pelvic floor as well as post-operative cicatrisation are complicating these procedures and increasing the risk of complications. A meta-analysis of TVT procedures revealed a higher risk of complications, especially of urgency, only in the group of older patients [46]. On the other hand, Walsh et al. [47] and Allahdin et al. [48] did not observe any impact of age on intraoperative and post-operative complications. However, Toozs-Hobson et al. [12] observed decreased effectiveness of the midurethral sling in the group of women above 85 years of age compared to younger patients.

Similarly to the findings of Salvarci and Gurbuz [49] and Pereira et al. [50], our study failed to reveal any impact of the BMI on the complication rate and the results of surgery, regardless of the procedure used. In contrast to these observations, Bernnand et al. [51] noted lower cure rates among obese patients versus non-obese women. We observed a significantly higher risk of intraoperative and early post-operative complications in such patients who have either never given birth or have given birth to one child only. Perhaps this surgical approach is more convenient in women who have had many deliveries. These phenomena should be supported by evidence from further studies. Our study confirmed the observation $[13,20,22]$ that TOT procedure operative time is significantly shorter than the operative time for the TVT procedure; however, hospital stay duration was similar in both groups. The shorter duration of TOT procedures surely comes from an absence of a cystoscopic examination that is required during the TVT procedure.

Similarly to other authors $[12,22,28,42,45,52-$ 57], a subjective cure and improvement was noted in over $80 \%$ of women in both groups. Based on an analysis of VAS and IIQ-7, there were no significant differences in quality of life between the groups at the 6-month follow-up. The improvement of life quality was also similar across both groups. The lack of assessment of sexual function before and after surgery is a limitation of this study. Stress urinary incontinence impairs quality of life, strongly affecting a woman's sexuality. Leakage during sexual activity and the resulting embarrassment felt by the person can interfere with and hamper their sex life, leading to depression and low self-esteem. Voiding disorders are often accompanied by a vaginal prolapse, enhancing its negative impact on sexual desire, arousal, orgasm, and dyspareunia [58, 59]. Surgery is the gold standard of SUI and pelvic organ prolapse (POP) treatment. However, there are still an insufficient number of trials on the impact of urogynaecological surgery on sexual function. Recent studies have reported a considerable improvement of QoL and sexual function after cystocele and vaginal fault prolapse correction [60, 61]. It is noteworthy that SUI and POP surgery not only affect the pelvic floor but also the whole physiological well-being of a woman, including her sexual function. Thus, a multidisciplinary approach is recommended for the treatment of pelvic floor disorders utilising validated questionnaires to cover the whole complexity of the problem. Quality of life and sexual dysfunction assessments should be incorporated into the therapeutic process of women affected by SUI and POP [62].

\section{Conclusions}

The TVT and TOT procedures are highly effective, minimally invasive methods of the treatment of female stress urinary incontinence. The TOT procedure 
is faster and carries a lower risk of complications than the TVT procedure yet has similar clinical efficacy.

The positive impact on the quality of life of both procedures is also comparable. However, it seems that the TOT surgery should be the preferred procedure for the following reasons: a significantly lower risk of intraoperative and early post-operative complications, a shorter surgery duration, and lower intraoperative blood loss. Older patients and women with gynaecological surgery in their medical history show a higher risk of intraoperative and post-operative complications, while a lower risk of complications has been observed in multiparous women who have had two or more deliveries.

\section{Conflict of interest}

The authors declare no conflict of interest.

\section{References}

1. Minassian VA, Drutz HP, Al-Badr A. Urinary incontinence as worldwide problem. Int J Gynaecol Obstet 2003; 82: 327-38.

2. Ulmsten UI, Petros PR. Intravaginal slingplasty (IVS): an ambulatory surgical procedure for treatment of female urinary incontinence. Scand J Urol Nephrol 1995; 29: 75-82.

3. Delorme E. Transobturator urethral suspension: mini-invasive procedure in the treatment of stress urinary incontinence. Prog Urol 2001; 11: 1306-13.

4. de Leval J. Novel surgical technique for treatment of female stress urinary incontinence: transobturator vaginal tape insideout. Eur Urol 2003; 44: 724-30.

5. Ustun Y, Engin-Ustun Y, Gungor M, et al. Tension-free vaginal tape compared with laparoscopic Burch urethropexy. J Am Assoc Gynecol Laparosc 2003; 10: 386-9.

6. Dean N, Herbison P, Ellis G, et al. Systematic review: laparoscopic colposuspension and tension-free vaginal tape: a systematic review. BJOG 2006; 113: 1345-53.

7. Fong ED M, Nitti VW. Review article: mid-urethral synthetic slings for female stress urinary incontinence. BJU Int 2010; 106: 596-608.

8. Novara G, Galfano A, Boscolo-Berto R, et al. Complication rates of tension-free midurethral slings in the treatment of female stress urinary incontinence: a systematic review and meta-analysis of randomized controlled trials comparing tension-free midurethral tapes to other surgical procedures and different devices. Eur Urol 2008; 53: 288-308.

9. Ford AA, Rogerson L, Cody JD, et al. Mid urethral sling operations for stress urinary incontinence in women. Cochrane Database Syst Rev 2017; 7: CD006375.

10. de Tayrac R, Madelenat P. Evolution of surgical routes in stress urinary incontinence. Gynecol Obstet Fertil 2004; 32: 1031-8.

11. Cavkaytar S, Kokonali MK, Guzel Al, et al. Comparison of TVT and TOT on urethral mobility and surgical outcomes in stress urinary incontinence with hypermobile urethra. Eur J Obstet Gynecol Reprod Biol 2015; 190: 36-40.
12. Toozs-Hobson P, Devani P, Pick J, et al. Does age affect the outcome of suburethral tape surgery? The importance of national registries in answering bigger questions. Int Urogynecol J 2016; 27: 1541-5.

13. Zhang Z, Zhu L, Xu T, et al. Retropubic tension-free vaginal tape and inside-out transobturator tape: a long-term randomized trial. Int Urogynecol J 2016; 27: 103-11.

14. Delmas V. Anatomical risk of transobturator suburethral tape in the treatment of female stress urinary incontinence. Eur Urol 2005; 48: 793-8.

15. Kim SO, Jung HS, Jang WS, et al. Measurement of the Q-tip angle before and after tension free vaginal tape-obturator (TVT-O): preoperative urethral mobility may predict surgical outcome. Int Urogynecol J 2013; 24: 1005-9.

16. Costantini E, Kocjanic E, Lazzeri M, et al. Long-term efficacy of the trans-obturator and retropubic mid-urethral slings for stress urinary incontinence: update from a randomized clinical trial. World J Urol 2016; 34: 585-93.

17. Gomes CM, Carvalho FL, Bellucci CHS, et al. Update on complications of synthetic suburethral slings. Int Braz J Urol 2017; 43: 822-34.

18. Barisiene M, Cerniauskiene A, Matulevicius A. Complications and their treatment after midurethral tape implantation using retropubic and transobturator approaches for treatment of female stress urinary incontinence. Videosurgery Miniinv 2018; 13: 501-6.

19. Keltie K, Elneil S, Monga A, et al. Complications following vaginal mesh procedures for stress urinary incontinence: an 8-year study of 92,246 women. Sci Rep 2017; 7: 12015.

20. Aigmüller T, Tammaa A, Tamussino K, et al. Retropubic vs. transobturator tension-free vaginal tape for female stress urinary incontinence: 3-month results of a randomized controlled trial. Int Urogynecol J 2014; 25: 1023-30.

21. Ben-Zvi T, Moore K, Haidar N, et al. An in-house Composix ${ }^{\top M}$-based pubovaginal sling trial for female stress urinary incontinence: five-year comparative follow-up to tension-free and transobturator vaginal tapes. Can Urol Assoc J 2017; 11: 275-80.

22. Luo DY, Wang KJ, Zhang HC, et al. Different sling procedures for stress urinary incontinence: a lesson from 453 patients. Kaohsiung J Med Sci 2014; 30: 139-45.

23. Hold $\varnothing B$, Verelst $M$, Svenningsen $R$, et al. Long-term clinical outcomes with the retropubic tension-free vaginal tape (TVT) procedure compared to Burch colposuspension for correcting stress urinary incontinence (SUI). Int Urogynecol J 2017; 28: 1739-46.

24. McLennan MT, Melick CF. Bladder perforation during tension-free vaginal tape procedures: analysis of learning curve and risk factors. Obstet Gynecol 2005; 106: 1000-4.

25. Ras L, Roskam SFN, Kruger PF, et al. Retrospective review of intra- and post-operative complications with minimal versus large space of Retzius infiltration at the time of retropubic TVT placement. Int Urogynecol J 2018 doi: 10.1007/s00192-018-3730-3.

26. McLennan MT, Barr SA, Melick CF, et al. Bladder perforation during tension-free vaginal tape procedures: abdominal versus vaginal approach. Female Pelvic Med Reconstr Surg 2012; 18 : 25-9. 
27. Chevrot A, Droupy S, Coffin G, et al. Long-term efficacy and safety of tension free vaginal tape in a historic cohort of 463 women with stress urinary incontinence. Int Urogynecol J 2017; 28: 827-33.

28. Fusco F, Abdel-Fattah M, Chapple CR, et al. Updated systematic review and meta-analysis of the comparative data on colposuspension, pubovaginal slings, and midurethral tapes in the surgical treatment of female stress urinary incontinence. Eur Urol 2017; 72: 567-91.

29. Giri SK, Wallis F, Drumm J, et al. A magnetic resonance imaging based study of retro-pubic hematoma after sling procedures: preliminary findings. BJU Int 2005; 96: 1067-71.

30. Chermansky CJ, Winters C. Complications of vaginal mesh surgery. Curr Opin Urol 2012; 22: 287-91.

31. Bianchi-Ferraro AM, Jarmy-DiBella ZIK, de Aquino-Castro R, et al. Randomized controlled trial comparing TVT-O and TVT-S for the treatment of stress urinary incontinence: 2 -year results. Int Urogynecol J 2014; 25: 1343-8.

32. Karmakar D, Mostafa A, Abdel-Fattah M. Long-term outcomes of transobturator tapes in women with stress urinary incontinence: E-TOT randomized controlled trial. BJOG 2017; 124: 973-81.

33. Ugurlucan FG, Erkan HA, Onal M, et al. Randomized trial of graft materials in transobturator tape operation: biological versus synthetic. Int Urogynecol J 2013; 24: 1315-23.

34. ElSheemy MS, Fathy H, Hussein HA, et al. Surgeon-tailored polypropylene mesh as a tension-free vaginal tape-obturator versus original TVT-O for the treatment of female stress urinary incontinence: a long-term comparative study. Int Urogynecol J 2015; 26: 1533-40.

35. Frohme C, Ludt F, Varga Z, et al. TOT Approach in stress urinary incontinence (SUI) - outcome in obese women. BMC Urology 2014; 14: 20.

36. Law TSM, Cheung RYK, Chung TK, et al. Efficacy and outcomes of transobturator tension-free vaginal tape with or without concomitant pelvic floor repair surgery for urinary stress incontinence: five-year follow-up. Hong Kong Med J 2015; 21: 333-8.

37. Brubaker L, Norton PA, Albo ME, et al. Adverse events over two years after retropubic or transobturator midurethral sling surgery: findings from the trial of midurethral sling (TOMUS) Study. Am J Obstet Gynecol 2011; 205: 498.e1-6.

38. Laurikainen E, Valpas A, Kivela A, et al. Retropubic compared with transobturator tape placement in treatment of urinary incontinence. Obstet Gynecol 2007; 109: 4-11.

39. Price N, Slack A, Khong S, et al. The benefit of early mobilisation of tension-free vaginal tape in the treatment of post-operative voiding dysfunction. Neurourol Urodyn 2009; 20: 855-8.

40. Ripperda CM, Kowalski JT, Chaudhry ZQ, et al. Predictors of early postoperative voiding dysfunction and other complications following a midurethral sling. Am J Obstet Gynecol 2016; 215: 656.e1-6.

41. Khan Z A, Nambiar A, Morley R, et al. Long-term follow-up of a multicentre randomised controlled trial comparing tension-free vaginal tape, xenograft and autologous fascial slings for the treatment of stress urinary incontinence in women. BJU Int 2015; 115: 968-77.
42. Canete P, Ortiz E, Domingo S, et al. Transobturator suburethral tape in the treatment of stress urinary incontinence: efficacy and quality of life 5 year follow up. Maturitas 2013; 74: 166-71.

43. Pereira E, Silva R, Gomes Olival V, et al. Overactive bladder symptoms after transobturator sling surgery for pure stress urinary incontinence: a cross-sectional comparative study. Urol Int 2018; 100: 428-33.

44. Vigil HR, Mallick R, Nitti VW, et al. Risk factors for urinary tract infection following mid urethral sling surgery. J Urol 2017; 197: 1268-73.

45. Djehdian LM, Araujo MP, Takano CC, et al. Transobturator sling compared with single-incision mini-sling for the treatment of stress urinary incontinence: a randomized controlled trial. Obstet Gynecol 2014; 123: 553-61.

46. Cetinel B, Demirkesen O. Risk factors influencing the complication rates of tension-free vaginal tape-type procedures. Curr Opin Obstet Gynecol 2005; 17: 530-4.

47. Walsh K, Generao SE, White MJ, et al. The influence of age on quality of life outcome in women following a tension free vaginal tape. J Urol 2004; 171: 1185-8.

48. Allahdin S, McKinley C, Mahmood TA. Tension-free vaginal tape: a procedure for all ages. Acta Obstet Gynaecol Scand 2004; 83: 937-40.

49. Salvarci A, Gurbuz R. Body mass index-based evaluation of 6-year outcomes after transobturator tension-free vaginal tape for female urinary incontinence. Urology 2017; 84: 40-7.

50. Pereira I, Valentim-Lourenco A, Castro C, et al. Incontinence surgery in obese women: comparative analysis of short- and long-term outcomes with a transobturator sling. Int Urogynecol J 2016; 27: 247-53.

51. Brennand EA, Tang S, Birch C, et al. Five years after midurethral sling surgery for stress incontinence: obesity continues to have an impact on outcomes. Int Urogynecol J 2017; 28: 621-8.

52. Majkusiak W, Pomian A, Tomasik P, et al. Does the suburethral sling change its location? Int J Urol 2017; 24: 848-53.

53. Maldonado PA, Kogutt BK, Wai CY. Patient satisfaction following midurethral sling surgeries. Curr Opin Obstet Gynecol 2014; 26: 404-8.

54. Maslow K, Gupta C, Klippenstein P, et al. Randomized clinical trial comparing TVT Secur system and trans vaginal obturator tape for the surgical management of stress urinary incontinence. Int Urogynecol I 2014; 25: 909-14.

55. Simsek A, Ozgor F, Kirecci SL, et al. Results of tension-free vaginal tape for recurrent stress urinary incontinence after unsuccessful transobturator tape surgery. I Obstet Gynaecol Res 2014; 40: 1764-9.

56. Nilsson CG, Palva K, Aarnio R, et al. Seventeen years' follow-up of the tension-free vaginal tape procedure for female stress urinary incontinence. Int Urogynecol J 2013; 24: 1265-9.

57. Onuk Ö. A minimally invasive modified technique for female stress urinary incontinence: transobturator tape without paraurethral dissection. Videosurgery Miniinv DOI: https://doi. org/10.5114/wiitm.2018.77715.

58. Vitale SG, La Rosa VL, Rapisarda AMC, et al. Sexual life in women with stress urinary incontinence. Oman Med J 2017; 32: 174-5.

59. Lagana AS, La Rosa VL, Rapisarda AMC, et al. Pelvic organ prolapse: the impact on quality of life and psychological well-being. J Psychosom Obstet Gynaecol 2018; 39: 164-6. 
60. Vitale SG, Caruso S, Rapisarda AM, et al. Biocompatibile porcine dermis graft to treat severe cystocele: impact on quality of life and sexuality. Arch Gynecol Obstet 2016; 293: 125-31.

61. Vitale SG, Lagana AS, Noventa M, et al. Transvaginal bilateral sacrospinous fixation after second recurrence of vaginal vault prolapse: efficacy and impact on quality of life and sexuality. Biomed Res Int 2018; 2018: 5727165.

62. Vitale SG, La Rosa VL, Rapisarda AMC, et al. The importance of a multidisciplinary approach for women with pelvic organ prolapse and cystocele. Oman Med I 2017; 32: 263-4.

Received: 7.01.2019, accepted: 16.02.2019 